\title{
Sonographic Evaluation of Normal Anatomy of Fetal Central Nervous System in Mid-Trimester
}

\author{
Mohammed H. Karrar Alsharif1,2*, Abubaker Y. Elamin ${ }^{2,3,4}$, Deya Eldin A. Mohamed ${ }^{4,5}$, \\ Khalid M. Taha ${ }^{6}$ \\ ${ }^{1}$ Anatomy Department, Salman Bin Abdulaziz University, Al-Kharj, KSA \\ ${ }^{2}$ Anatomy Department, Faculty of Medicine, University of Science and Technology, Khartoum, Sudan \\ ${ }^{3}$ Emergency Medical Specialist Department, Al-Ghad International Colleges for Applied Medical Sciences, Al \\ Madinah Al Munawarah, KSA \\ ${ }^{4}$ Anatomy Department, School of Medicine, Ahfad University for Women, Omdurman, Sudan \\ ${ }^{5}$ Department of Medical Imaging, Al-Ghad International College for Applied Medical Sciences, Dammam, KSA \\ ${ }^{6}$ Anatomy Department, Faculty of Medicine Karary University, Omdurman, Sudan \\ Email: "dr.anatomy83@yahoo.com, m.alshrif@sau.edu.sa
}

Received 27 December 2014; accepted 20 January 2015; published 26 January 2015

Copyright (C) 2015 by authors and Scientific Research Publishing Inc.

This work is licensed under the Creative Commons Attribution International License (CC BY).

http://creativecommons.org/licenses/by/4.0/

(c) (i) Open Access

\begin{abstract}
The central nervous system is a common site for congenital anomalies. Neural tube defects (NTDs) such as anencephaly, encephalocele and spina bifida are among the most common central nervous system congenital anomalies. They result from failure of closure of the neural tube during embryonic development. The neural tube formation starts during the fourth week (22 - 23 days) after fertilization and fuses approximately between the days 25th and 27th. Most of NTDs result from genetic factors and environmental factors which are poorly understood. Diagnostic sonography can show a detailed visualization of the fetal intracranial anatomy such as the cerebral hemispheres, midbrain, thalami, and lateral ventricles. They also can measure the ratio between lateral ventricular and cerebral hemispheric width. It might show as well, the ratio between gestation, the rapid growth of the cerebral hemispheres and the expansion of the cerebral ventricles. The ultrasound during pregnancy plays a prominent and influential role in the prenatal evaluation of the central nervous system. It gives an excellent window for viewing and evaluating the fetal central nervous system during the second trimester through the lateral ventricles and transthalamic view, thus effectively contributing in the diagnosis and treatment of its congenital anomalies.
\end{abstract}

\footnotetext{
"Corresponding author.
}

How to cite this paper: Alsharif, M.H.K., Elamin, A.Y., Mohamed, D.A. and Taha, K.M. (2015) Sonographic Evaluation of Normal Anatomy of Fetal Central Nervous System in Mid-Trimester. Forensic Medicine and Anatomy Research, 3, 32-38. http://dx.doi.org/10.4236/fmar.2015.31007 


\section{Keywords}

\section{Sonographic Evaluation, Fetal Nervous System, Second Trimester, Neural Tube Defects}

\section{Introduction and Developmental Background}

The central nervous system (CNS) has an ectodermal origin and appears as neural plate in the middle of the third week of development. The edges of the plate start to fold and form the neural folds and they approach each other in the midline. Finally they fuse to form the neural tube. The proximal part of the neural tube closes approximately at day 25 and the caudal or distal end closes at day 27. The CNS then becomes broader, showing a number of dilatations in the cephalic part of the tube to form the brain or cephalic part of CNS whereas the caudal part is elongated to form the spinal cord or the caudal part of CNS [1].

The brain consists originally of three vesicles: the rhombencephalon (hindbrain), mesencephalon (midbrain), and prosencephalon (forebrain). The rhombencephalon is divided into two parts: (a) the myelencephalon, which forms the medulla oblongata and (b) the metencephalon, with its typical basal (efferent) and alar (afferent) plates, later forming the cerebellum and the pons. The mesencephalon, or midbrain, resembles the spinal cord with its basal efferent and alar afferent plates [1].

The diencephalon, situated in the posterior aspect of the forebrain, consists of a thin roof plate and a thick alar plate in which the thalamus and hypothalamus develop. It shares in the formation of the pituitary gland, which also develops from Rathke's pouch. Rathke's pouch forms the adenohypophysis, the intermediate lobe, and pars tuberalis, and the diencephalon forms the posterior lobe, the neurohypophysis, which contains neuroglia and receives nerve fibers from the hypothalamus [1].

The telencephalon is the most rostral part of the brain vesicle that consists of two lateral outpocketings, the cerebral hemispheres, and a median portion, the lamina terminalis. The ventricular system, containing cerebrospinal fluid, extends from the lumen in the spinal cord to the fourth ventricle in the rhombencephalon, through the narrow duct in the mesencephalon, and to the third ventricle in the diencephalon. By way of the foramina of Monro, the ventricular system extends from the third ventricle into the lateral ventricles of the cerebral hemispheres. Cerebrospinal fluid is produced in the choroid plexus of the third, fourth, and lateral ventricles. Blockage of cerebrospinal fluid in the ventricular system or subarachnoid space may lead to hydrocephalus [1].

Ultrasonography is widely used for the prenatal evaluation of growth and anatomy as well as for the management of multiple gestations. This procedure provides diagnostic findings that often facilitate the management of problems arising in later pregnancy [1].

CNS malformations are some of the most common of all congenital abnormalities. Neural tube defects are the most frequent CNS malformations and amount to about 1 - 2 cases per 1000 births. The incidence of intracranial abnormalities with an intact neural tube is uncertain as probably most of these escape detection at birth and only become manifest in later life. Long-term follow-up studies suggest however that the incidence may be as high as one in 100 births [2].

The World Health Organization (WHO) concluded that impaired fetal growth had many causes related to: genetic factors, maternal characteristics such as nutrition, lifestyle including smoking, age and disease; complications of pregnancy; and the physical, social and economic environment [3] [4].

A mid-trimester fetal ultrasound scan serves as an important baseline against which later scans may be compared for the evaluation of growth and health of the fetus. Ultrasonography can also be used to detect congenital anomalies [5] [6].

During the first trimester, the main structures that can be visualized by ultrasound are the brain vesicles. About 10 - 11 weeks of gestation, the lateral ventricle and choroid plexus can be observed [7]. The second trimester gives an excellent window for the study of fetal brain and spine [8].

Romero, R., et al. (2002) used different views through different life stages of the fetus. The study results showed that at 16 weeks of gestation, the lateral ventricles occupy most of the cerebralhemispheres and are partially filled with the echogenic choroid plexuses. The axial view has been used to derive nomograms for the normal size of the ventricles [9].

The second scanning plane passes through the frontal horns, atria, and occipital horns of the lateral ventricles. 
At 18 weeks, the atria are round and are entirely filled with the choroid plexus. Later, the atria decrease in size. The occipital horns appear as a fluid-filled posterior of the atria. It is possible to visualize the frontal horns of the lateral ventricles. The frontal horns are usually separated by a widely patent cavumseptipellucidi [10].

In the third axial section the thalami appear. The slit-like third ventricle can be seen. It is possible to visualize the frontal horns of the lateral ventricles. The frontal horns are usually separated by a widely patent cavumseptipellucidi. The fourth axial plane passes through the midbrain and the chiasmatic cistern and only part of the temporal horn can be seen [9].

Johnson, M. L. et al. (1980) managed to show a detailed visualization of fetal intracranial anatomy by ultrasonography. The study showed that structures such as the midbrain, thalami, and lateral ventricles can be routinely imaged. The study also labeled that the measurements of the ratio between lateral ventricular width and cerebral hemispheric width demonstrate a steady decrease from a mean of $56 \%$ at $15^{\text {th }}$ week of gestation to $28 \%$ at term of birth, reflecting the relatively more rapid growth of the cerebral hemispheres as compared with the cerebral ventricles. This article described the axial fetal cranial anatomy as demonstrated sonically and included a table for normal fetal ventricular size at various gestational ages, based on evaluation of 196 normal fetuses [10].

Ultrasound techniques also revealed great usefulness in expressing and diagnosing the brain abnormalities. Achiron, R. et al. (1997) evaluated the clinical significance of in utero detection of fetal cerebral lateral ventricular asymmetry. This study was conducted on 7200 pregnant women and focused on the fetuses with asymmetry brain findings. It concluded that any ventricular asymmetry is an indicator of available clinical data [11]. Another retrospective study made by Nicolaides, K.H. et al. (1986), which was conducted on 70 fetuses at 16 23 weeks of gestational age, showed the applicability of using the ultrasound in diagnosing open spina bifida in these fetuses [12].

The selected view is chosen accordingly by ultrasound to show the exact brain parts. One study examined different approaches for measuring the lateral ventricle. It revealed that axial approach has more advantages over the cranial view, in which the distal ventricle is only clearly visible and measurable in this view [13].

Transabdominal sonography is the technique of choice to investigate the fetal CNS during late first, second and third trimesters of gestation in low risk pregnancies. The examination should include the evaluation of the fetal head and spine. Two axial planes allow visualization of the cerebral structures relevant to assess the anatomic integrity of the brain [14]. These planes are commonly referred to as the transventricular plane and the transcerebellar plane. A third plane, the so-called transthalamic plane is frequently added, mostly for the purpose of biometry. Structures that are usually noted in a basic ultrasound examination of the fetal central nervous system include the following: head shape, lateral ventricles (Figure 1(a)), cavumseptipellucidi, thalami (Figure 1(b)), cerebellum (Figure 1(c)), cisterna magna and spine [15] (Figure 1(c)). Timor-Tritsch, I. E. et al. (2000) conducted a study using the three-horn view through 2D and 3D ultrasound techniques. The study concluded that use of these ultrasound techniques provided diagnostic and clinically useful information [16].

Although many countries have developed local guidelines for the practice of fetal ultrasonography, there are still many areas of the world where they have not been implemented yet.

As mentioned before, the central nervous system anomalies are quite common, so this review article aims to highlight local guidelines for qualitative and quantitative results, to show sonographic measurements of the normal anatomy of fetal nervous system in the second trimester of pregnancy. Sonographic evaluation will help and play an important role in early detection and diagnosis of congenital anomalies affecting the central nervous system. On the other hand, it will also help in reduction of morbidity and mortality rate in new born.

The following is an overview of some of the morphological and volumetric measurements used by specialists in the field of obstetrics and gynecology regarding normal fetal skull and nervous system.

1) Head circumference calculated from outer to outer biparietal diameter (BPD) and occipitofrontal diameter (OFD) measurements

Traditionally this is the most widely used parameter in the estimation of gestational age (Table 1, Figure 3). Head circumference (HC) can be measured from one of the following two sections:

- Lateral ventricles view

- Thalami view

The charts and tables represent those recommended by BMUS for routine use.

Also these views can be used to identify some anatomical structures of nervous system. In the lateral ventricles view, the rugby-football-shaped skull might appear with narrow anterior edge and wider posterior edge, 

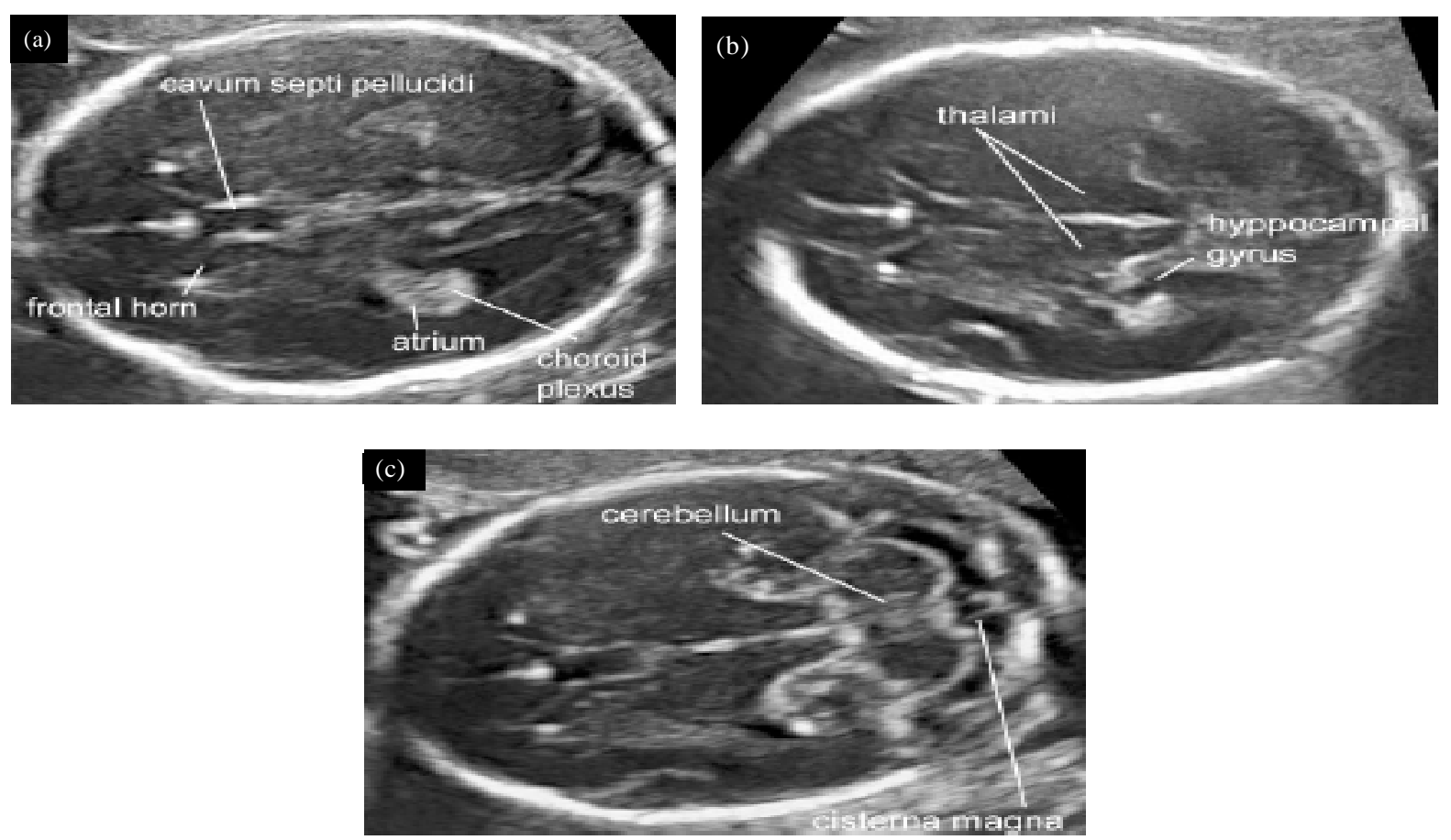

Figure 1. Axial view of the fetal head. (a) Transventricular plane; (b) Transthalamic plane; (c) Transcerebellar plane.

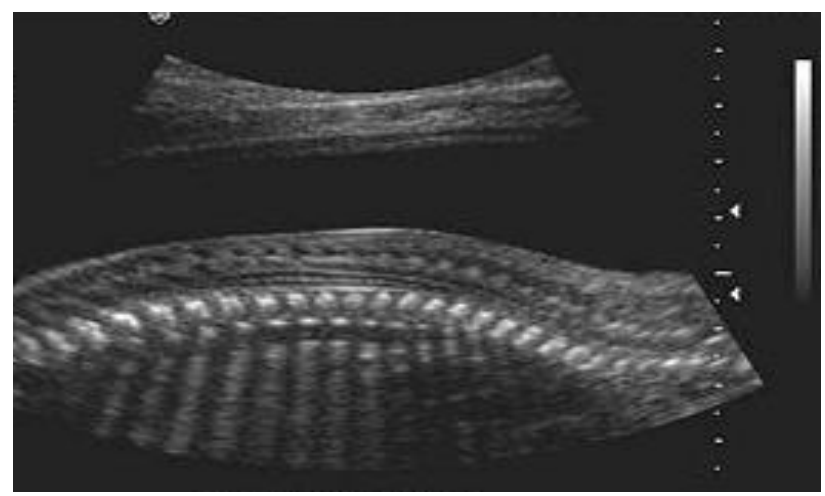

Figure 2. Fetal spine.

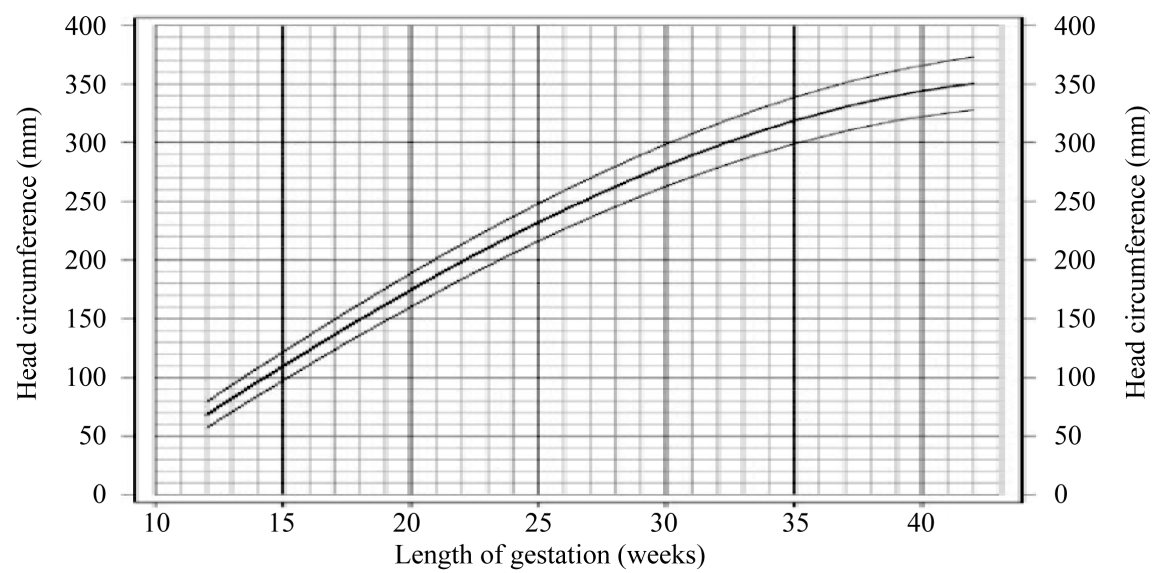

Figure 3. Head circumference size chart [17]. 
Table 1. Head circumference size table [17].

\begin{tabular}{|c|c|c|c|}
\hline \multicolumn{4}{|c|}{ Head circumference (mm) } \\
\hline GA (weeks) & 50th centile & 5 th centile & 95th centile \\
\hline 12 & 68.1 & 75.1 & 79.2 \\
\hline 13 & 82.2 & 70.8 & 93.6 \\
\hline 14 & 96.0 & 84.2 & 107.8 \\
\hline 15 & 109.7 & 79.5 & 121.9 \\
\hline 16 & 123.1 & 110.6 & 135.7 \\
\hline 17 & 136.4 & 123.4 & 149.3 \\
\hline 18 & 149.3 & 136.0 & 162.7 \\
\hline 19 & 162.0 & 148.3 & 175.7 \\
\hline 20 & 174.5 & 160.4 & 188.6 \\
\hline 21 & 186.6 & 172.1 & 202.1 \\
\hline 22 & 198.5 & 183.6 & 213.3 \\
\hline 23 & 210.0 & 194.8 & 225.3 \\
\hline 24 & 221.2 & 205.6 & 236.9 \\
\hline 25 & 232.1 & 216.1 & 248.1 \\
\hline 26 & 242.6 & 226.2 & 259.0 \\
\hline 27 & 252.7 & 235.9 & 269.5 \\
\hline 28 & 262.5 & 245.3 & 279.6 \\
\hline 29 & 271.8 & 254.3 & 289.4 \\
\hline 30 & 280.7 & 262.8 & 298.7 \\
\hline 31 & 289.2 & 270.9 & 307.6 \\
\hline 32 & 297.3 & 278.6 & 316.0 \\
\hline 33 & 304.9 & 285.8 & 324.0 \\
\hline 34 & 312.0 & 292.6 & 331.5 \\
\hline 35 & 318.7 & 298.8 & 338.5 \\
\hline 36 & 324.8 & 340.6 & 345.0 \\
\hline 37 & 330.4 & 309.8 & 351.0 \\
\hline 38 & 335.5 & 314.5 & 356.5 \\
\hline 39 & 340.0 & 318.7 & 361.4 \\
\hline 40 & 344.0 & 322.3 & 365.8 \\
\hline 41 & 347.4 & 325.3 & 369.6 \\
\hline 42 & 350.3 & 327.7 & 372.8 \\
\hline
\end{tabular}

also the cavum septum pellucidum, thalami, corpus callosum, and the anterior horns of lateral ventricle are visible; all or parts of posterior horns or atrium might appear, containing choroid that appears as a rounded, hyperechoic structure. The choroid plexus provides a very useful landmark with which to identify the position and extent of the posterior horn (Figure 4).

In the thalami view, the skull also appears like rugby-football-shaped with narrow anterior edge and wider posterior edge; the cavum septum pellucidum bisects the midline one-third of the distance from the synciput to the occiput 13, the thalami and the basal cisterns also being visible.

2) The fetal spine

The ultrasound makes it easy to evaluate the normal fetal spine in utero and that due ossification centers within the vertebrae produce high-level echoes. The spine appears as two parallel lines of small echoes that come together at the sacrum. These echoes are thought to represent the ossification center of one lamina of the vertebral arch posteriorly (i.e. immediately under the skin surface) and the ossification center of the same verte- 


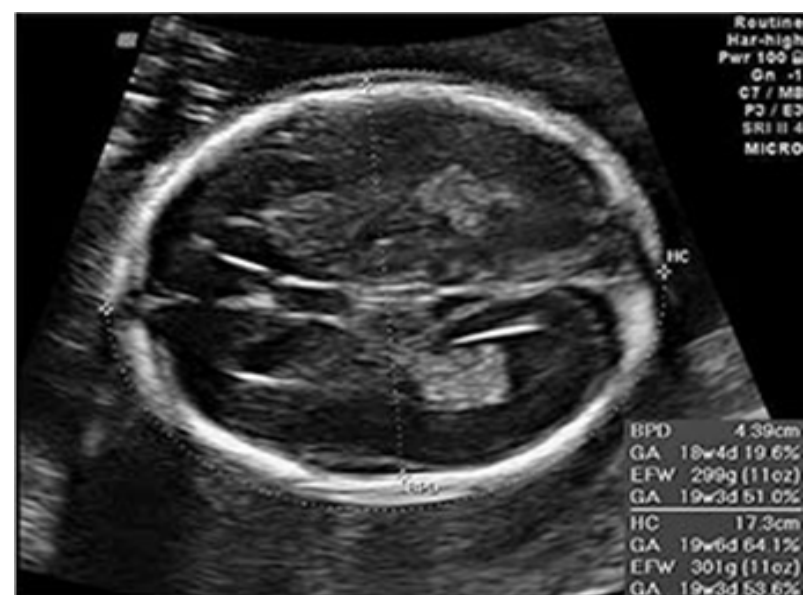

Figure 4. Transverse section of the fetal head.

bral body anteriorly [18].

\section{Conclusion}

It is important to determine the qualitative and quantitative evaluation of normal anatomy of fetal central nervous system and to verify the degree of similarity between the measurements of fetal central nervous system and compare these findings. This will provide local guidelines and form a database for sonographic evaluation of fetal central nervous system. Finally by knowing the normal measurements, we can predict and diagnose by ultrasonography, the congenital anomalies affecting the fetal nervous system.

\section{References}

[1] Sadler, T.W. (2011) Langman’s Medical Embryology. Lippincott Williams and Wilkins, Philadelphia.

[2] Myrianthopoulos, N.C. (1977) Epidemiology of Central Nervous System Malformations. Handbook of Clinical Neurology. Elsevier, Amsterdam.

[3] WHO (2005) Regional Consultation towards the Development of a Strategy for Optimizing Fetal Growth and Development. WHO, Cairo.

[4] Barker, D.J., Gluckman, P.D., Godfrey, K.M., Harding, J.E., Owens, J.A. and Robinson, J.S. (1993) Fetal Nutrition and Cardiovascular Disease in Adult Life. Lancet, 341, 938-941. http://dx.doi.org/10.1016/0140-6736(93)91224-A

[5] Schwarzler, P., Senat, M.V., Holden, D., Bernard, J.P., Masroor, T. and Ville, Y. (1999) Feasibility of the SecondTrimester Fetal Ultrasound Examination in an Unselected Population at 18, 20 or 22 Weeks of Pregnancy: A Randomized Trial. Ultrasound in Obstetrics and Gynecology, 14, 92-97. http://dx.doi.org/10.1046/j.1469-0705.1999.14020092.x

[6] Goldberg, J.D. (2004) Routine Screening for Fetal Anomalies: Expectations. Obstetrics Gynecology Clinics of North America, 31, 35-50. http://dx.doi.org/10.1016/S0889-8545(03)00118-9

[7] Blaas, H.G., Eik-Nes, S.H., Kiserud, T., Berg, S. and Angelson, B. (1995) Three-Dimensional Imaging of the Brain Cavities in Human Embryos. Ultrasound in Obstetrics and Gynecology, 5, 228-232. http://dx.doi.org/10.1046/j.1469-0705.1995.05040228.x

[8] Bronshtein, M. and Zimmer, E. (2001) Transvaginal Sonography of Normal and Abnormal Fetus. The Parthenon Publishing Group Limited, Casteron Hall.

[9] Romero, R., Pilu, G., Jeanty, P., Ghidini, A. and Hobbins, J.C. (2002) Prenatal Diagnosis of Congenital Anomalies. Appleton \& Lange, Norwalk, Connecticut/San Mateo.

[10] Johnson, M.L., Dunne, M.G., Mack, L.A. and Rashbaum, C.L. (1980) Evaluation of Fetal Intracranial Anatomy by Static and Real-Time Ultrasound. Journal of Clinical Ultrasound, 8, 311-318. http://dx.doi.org/10.1002/jcu.1870080405

[11] Achiron, R., Yagel, S., Rotstein, Z., Inbar, O., Mashiach, S. and Lipitz, S. (1997) Cerebral Lateral Ventricular Asymmetry: Is This a Normal Ultrasonographic Finding in the Fetal Brain? Obstetrics \& Gynecology, 89, 233-237. http://dx.doi.org/10.1016/S0029-7844(96)00506-6 
[12] Nicolaides, K.H., Gabbe, S.G., Campbell, S. and Guidetti, R. (1986) Ultrasound Screening for Spina Bifida: Cranial and Cerebellar Signs. The Lancet, 328, 72-74. http://dx.doi.org/10.1016/S0140-6736(86)91610-7

[13] Katorza, E., Duvdevani, N., Jacobson, J.-M., Gilboa, Y., Hoffmann, C. and Achiron, R. (2014) Coronal Approach for Measuring both Fetal Lateral Ventricles: Is There an Advantage over the Axial View? Prenatal Diagnosis, 34, 279-284. http://dx.doi.org/10.1002/pd.4310

[14] Filly, R.A., Cardoza, J.D., Goldstein, R.B. and Barkovich, A.J. (1989) Detection of Fetal Central Nervous System Anomalies: A Practical Level of Effort for a Routine Sonogram. Radiology, 172, 403-408. http://dx.doi.org/10.1148/radiology.172.2.2664864

[15] Falco, P., Gabrielli, S., Visentin, A., Perolo, A., Pilu, G. and Bovicelli, L. (2000) Transabdominal Sonography of the Cavum Septum Pellucidum in Normal Fetuses in the Second and Third Trimesters of Pregnancy. Ultrasound in Obstetrics and Gynecology, 16, 549-553. http://dx.doi.org/10.1046/j.1469-0705.2000.00244.X

[16] Timor-Tritsch, I.E., Monteagudo, A. and Mayberry, P. (2000) Three-Dimensional Ultrasound Evaluation of the Fetal Brain: The Three Horn View. Ultrasound in Obstetrics and Gynecology, 16, 302-306. http://dx.doi.org/10.1046/j.1469-0705.2000.00177.x

[17] Chitty, L.S., Altman, D.G., Henderson, A. and Campbell, S. (1994) Charts of Fetal Size: 2. Head Measurements. British Journal of Obstetrics and Gynaecology, 101, 35-43. http://dx.doi.org/10.1111/j.1471-0528.1994.tb13007.x

[18] Chudleigh, T. and Thilaganathan, B. (2004) Obstetric Ultrasound: How, Why and When. Churchill Livingstone, London. 
Scientific Research Publishing (SCIRP) is one of the largest Open Access journal publishers. It is currently publishing more than 200 open access, online, peer-reviewed journals covering a wide range of academic disciplines. SCIRP serves the worldwide academic communities and contributes to the progress and application of science with its publication.

Other selected journals from SCIRP are listed as below. Submit your manuscript to us via either submit@scirp.org or Online Submission Portal.
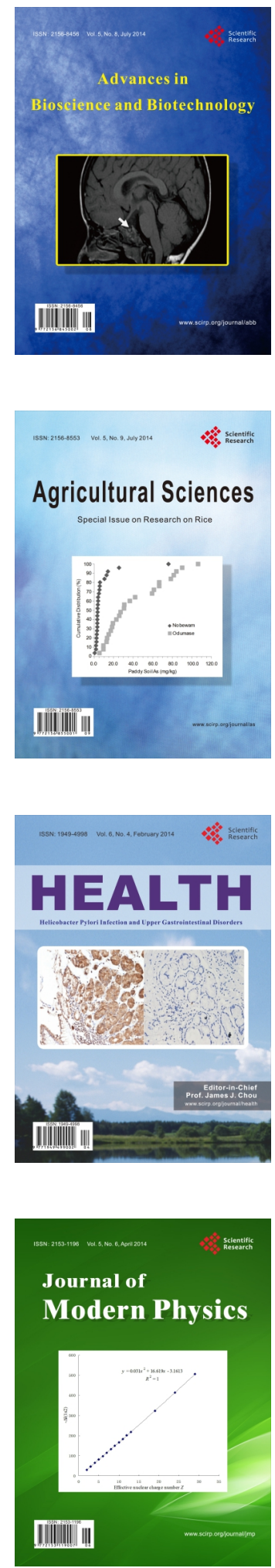
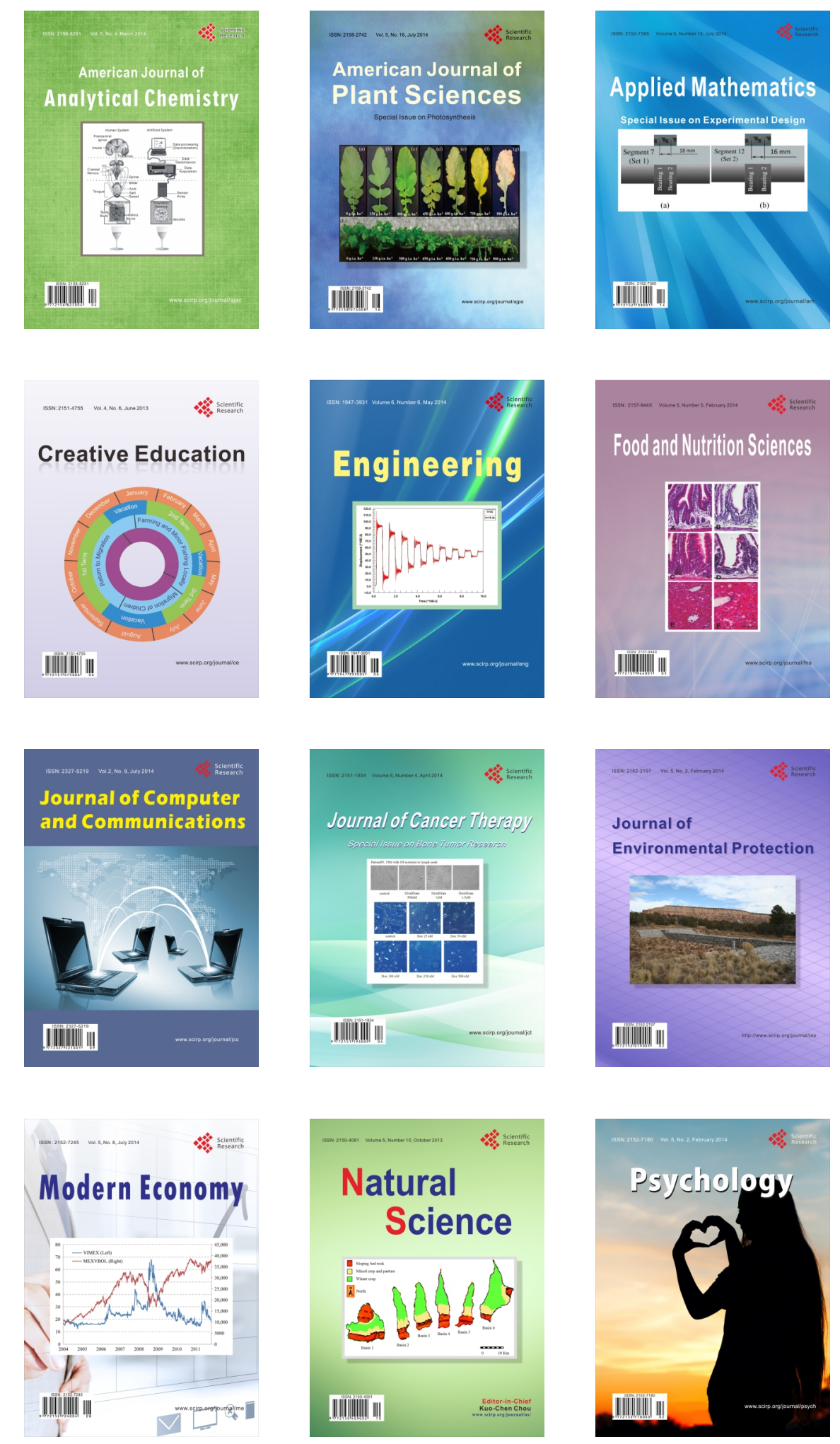